\title{
A PERCEPÇÃO DE PROFESSORES E ESTUDANTES SOBRE A SALA DE AULA DE ENSINO SUPERIOR: EXPECTATIVAS E CONSTRUÇÃO DE RELAÇÕES NO CURSO DE QUÍMICA DA UFMG
}

\section{Teachers and the students' perception about College classrooms: expectations and relations construction in the UFMG Chemistry Undergraduate Program}

\author{
Ana Luiza de Quadros ${ }^{1}$ \\ Cintia de Melo Lopes ${ }^{2}$ \\ Fabio Augusto Brandão da Silva ${ }^{3}$ \\ Joane Mariela Miari Correa ${ }^{4}$
}

\author{
Jucelia Marisa Pio $^{5}$ \\ Naira de Oliveira Torres ${ }^{6}$ \\ Patricia Leal Pinto ${ }^{7}$ \\ Roberta Kelly Nogueira ${ }^{8}$
}

Resumo: A sala de aula é um espaço de formação humana, constituído pela diversidade e heterogeneidade. As relações pedagógicas que nela acontecem são impregnadas de subjetividade. Com o objetivo de entender, por meio de dados empíricos, quais são as percepções de estudantes e professores acerca das relações que se desenvolvem em sala de aula, aplicamos um instrumento de coleta de dados a professores e estudantes do curso superior de Química da Universidade Federal de Minas Gerais UFMG. A nossa análise dos dados mostrou que as expectativas de estudantes e professores divergem em alguns pontos e que, provavelmente, não há um "contrato" preestabelecido sobre o papel de cada um. A afetividade, presente em toda relação humana, também permeia a relação professor/estudante, não sendo bem entendida. Há, inclusive, um certo "receio" de envolvimento quando a relação afetiva é vista como uma relação de amizade ou empatia.

Palavras-chave: Ensino Superior. Relação professor e estudantes. Afetividade.

Abstract: The classroom is a space for human formation, consisting of diversity and heterogeneity. The pedagogic relations that happen inside are full of subjectivity. With the goal to understand, through empirical data, which are the students and teachers' perceptions about the relationships that unfold in the classroom, we apply a data collection instrument to teachers and students of college classes of Chemistry undergraduate majors in UFMG. Our data analysis shows that the teachers and students' expectations diverge in some ways and, probably that is no pre-established "contract" of each one's role. The affectivity in every human relationship and including that which surrounds the teacher/ students' relationship is not well understood. We noted that there is, also, certain "apprehension" about involvement when the affective relationship is understood as a relationship of friendship or empathy.

Keywords: College. Teachers and students' relationship. Affectivity.

\footnotetext{
${ }^{1}$ Licenciada em Química. Mestre em Educação nas Ciências. Docente, Departamento de Química, Instituto de Ciências Exatas, Universidade Federal de Minas Gerais (UFMG). Belo Horizonte, MG, Brasil.

<aquadros@qui.ufmg.br>

${ }^{2}$ Licenciada em Química. Especialista em Ensino de Ciências. Professora de Química, Escola Estadual Prof. G. Azevedo Lage. Belo Horizonte, MG, Brasil. <cintiachem@yahoo.com.br>

3,4,5,67,8 Licenciadosem Química. <fabs@qui.grad.ufmg.br>; <quiblza@ufmg.br>; <juceliamp@ufmg.br>; <naira@qui.grad.ufmg.br>; <patricialeal@ufmg.br>; <robertakn@ufmg.br>
}

${ }^{1}$ Departamento de Química. Instituto de Ciências Exatas - UFMG

Av. Antonio Carlos, 6627

Pampulha - Belo Horizonte, MG

$31.270-901$ 
Quadros, A. L. et al.

\section{Introdução}

A sala de aula é um espaço de formação humana, de vivência e convivência e de relações pedagógicas que se destinam ao crescimento individual dos sujeitos na interação com o outro e com o conhecimento. É um espaço constituído pela diversidade e heterogeneidade de ideias, valores e crenças. Assim, é impregnado de significado e nele "a experiência pedagógica - o ensinar e o aprender - é desenvolvida no vínculo: tem uma dimensão histórica, intersubjetiva e intra-subjetiva" (VALDEZ, 2002, p. 24).

É nessa sala de aula que se desenvolvem as mais variadas discussões, inclusive sobre ela mesma. Foram em discussões surgidas numa disciplina de graduação do curso de Licenciatura em Química, na qual o ensinar e aprender química eram objetos de investigação, que a visão de cada um dos sujeitos sobre a sala de aula mostrou-se conflituosa, sobretudo no que concerne às expectativas do professor em relação aos estudantes e destes com o professor.

Os estudantes apresentavam uma visão pouco refletida sobre o trabalho da sala de aula, marcada por momentos nos quais percebiam a figura do professor de Ensino Superior como autoritária ou pouco aberta ao diálogo e às relações de afetividade. Percebiam-no com uma atenção quase que exclusiva ao conhecimento com o qual trabalhava.

Ao compararem o foco de atenção do professor de Ensino Superior com o do professor da Educação Básica, algumas posturas ficaram mais explícitas: o professor das séries iniciais tem uma relação de afetividade com os sujeitos aprendizes, focando neles o seu trabalho. À medida que outros níveis de ensino vão sendo alcançados acontecem mudanças significativas nessa relação. O professor passa, gradativamente, a focar o seu trabalho no conteúdo.

Provavelmente essa mudança seja percebida de diferentes maneiras pelo professor e pelo estudante: enquanto este último se sente, de certa forma, "abandonado" pelo professor, é visto por ele como uma pessoa que precisa desenvolver sua autonomia na busca de outras formas de - no caso da química - entender o mundo material em que vive.

Sendo a sala de aula um espaço no qual diferentes sujeitos compartilham aprendizagens, por meio de relações que se constroem na interação, pesquisar esse cotidiano certamente constitui um desafio. E, se tratando de estudantes de um curso de licenciatura - futuros professores, portanto -, entender como se constroem as relações pedagógicas em sala de aula é ainda mais importante.

Considerando que a relação entre professores e alunos, em sala de aula, nos cursos de graduação é, muitas vezes, uma relação de "distanciamento", julgamos que, para entender um pouco dessa relação, precisávamos responder às seguintes questões: o que o professor de Ensino Superior esperaria dos estudantes para desenvolver uma boa aula? O que os estudantes de graduação esperariam de um bom professor, na sala de aula, para dinamizar ou tornar mais eficiente a aprendizagem?

Para auxiliar no entendimento destas questões, dirigimos o nosso olhar para o que outros educadores têm apontado sobre isso. 


\section{Visitando outras pesquisas}

Apesar de vivermos num mundo em que as relações de comunicação têm sido modificadas pela "rapidação" das tecnologias, sobretudo de informação e comunicação, nem tudo tem mudado tão rapidamente. Essas tecnologias estão inseridas na maioria das escolas e, em algumas delas, na própria sala de aula. Apesar disso, a relação entre professores e aprendizes continua se dando - e não poderia ser diferente - predominantemente pelas interações linguísticas em suas diversas formas, ou seja, na conversa, no diálogo, na "negociação" de ideias ou no discurso unilateral.

Quando falamos de discurso unilateral, estamos nos referindo a um discurso de autoridade, no qual o professor, além de planejar o conteúdo a ser desenvolvido nas aulas, ocupa praticamente todo o tempo destinado à aula, reproduzindo o discurso científico. Mesmo sendo, na maioria das vezes, um discurso explicativo ou descritivo, vem carregado de emoções que, apesar de não planejadas pelo professor, podem ser percebidas pelo estudante. A entonação da voz do professor, a posição física que ocupa, a forma de dirigir o olhar, entre outros aspectos, podem ser entendidos como linguagem que expressa emoções.

Essa relação pedagógica de sala de aula, na qual o professor assume a maior parte do discurso, é assimétrica por natureza. Ao professor está destinada as tarefas de: selecionar conteúdos que considera importante, ocupar um lugar de destaque na sala de aula, e iniciar e pôr fim às discussões de conteúdo. Isso estabelece, naturalmente, um poder ao professor maior do que ao aprendiz.

Segundo Brants (2004, p. 2),

[...] a assimetria é uma característica inerente à relação professor/alunos, em virtude, por exemplo, da diferença de idade, da diferença de poder que é conferido a cada um destes interagentes, pela própria instituição escolar. Ao professor, em geral, é garantido o poder para selecionar os conteúdos que serão ensinados aos alunos, bem como o seu modo de transmissão.

Sobre essa assimetria, Dias (2007) comenta que a sala de aula é um ambiente onde todos possuem um papel social, com funções predeterminadas. O professor, normalmente, controla e dirige o turno por meio do poder que lhe é incumbido institucionalmente. Ele precisa explicar conceitos com clareza, compartilhar informações e motivar a reflexão a partir desses conceitos e informações. Segundo a pesquisadora, quando o professor não consegue atingir seus objetivos e, ao mesmo tempo, sofre várias interrupções dos alunos, as relações de poder e solidariedade podem ser colocadas em jogo.

Dias (2007) também afirma que o poder de um professor na interação da sala de aula está diretamente ligado a fatores como idade, sexo, personalidade, classe social, cultura, e que as conversações que nela ocorrem trazem marcas da realidade subjetiva. Quando os papéis e posições dos indivíduos entram em contradição ou são incompatíveis, podem surgir problemas comunicativos que resultem em transgressões, desafios, desajustes, mal-entendidos, o que vai requerer, novamente, estratégias de ajuste e marcas de poder. 
É esse poder, naturalmente conferido ao professor, que pode não estar sendo, ao que nos parece, devidamente usado ou entendido. O professor, ao sentir seu poder questionado, impõe novas "normas" na relação pedagógica de sala de aula. Os estudantes, que cada vez mais parecem estar querendo ampliar seu espaço nessa relação, sentem-se oprimidos ou num espaço/tempo que entendem ser menor do que deveria.

Em pesquisa realizada na escola fundamental, de $5^{a}$ a $8^{a}$ série, sobre a relação professor e aluno, Panizzi (2004, p. 11), afirma que:

O aluno tem a necessidade de ver o professor não somente como alguém que vai lhe transmitir conhecimentos e preocupado com as explicações sobre determinado conteúdo, mas como alguém que, comprometido com a ação que realiza, percebe o aluno como um ser importante, com idéias e sentimentos que podem ser partilhados com ele. Nesse processo de interação humana, de intercâmbio, o conhecimento estruturado do professor, sua forma de expressão mais formal, seus valores e concepções se misturam aos saberes não sistematizados e empíricos dos alunos, aos seus valores e linguagem próprios de seu ambiente cultural.

Cada um dos estudantes presentes na sala de aula se constrói a partir das relações que estabelece entre o mundo externo a ele - estruturado pela cultura e pelas condições sociais - e seu mundo interno. E isso se dá tanto no aspecto cognitivo como nos aspectos de ordem mais afetiva, tais como desejos, sentimentos, emoções e outros.

Segundo Panizzi (2004, p. 14),

[...] a escola constitui-se num espaço essencialmente educativo, cuja função principal é a de mediar o conhecimento, possibilitar ao educando o acesso e a reconstrução do saber. Essa função está imbricada inexoravelmente às relações, pois a transmissão do conhecimento se dá na interação entre pessoas. Assim, nas relações ali estabelecidas, professor/aluno, aluno/aluno, o afeto está presente. Um dos componentes essenciais para que esta relação seja significativa e represente uma parceria no processo ensino-aprendizagem, é o diálogo.

Apesar de ser essa uma percepção advinda da Educação Básica, ela também pode ser considerada para o Ensino Superior, pois, de acordo com Freire (1996, p. 162-163),

[...] não importa com que faixa etária trabalhe o educador ou a educadora. O nosso é um trabalho com gente miúda, jovem ou adulta, mas gente em permanente processo de busca. Gente formando-se, mudando, crescendo, reorientando-se, melhorando, mas porque gente, capaz de negar os valores, de distorcer-se, de recuar, de transgredir. 
A percepção de professores e estudantes ...

Em pesquisa desenvolvida por Quadros et al. (2006), com professores do Ensino Superior, a participação dos alunos foi considerada como motivadora do trabalho do professor. Nessa pesquisa, alguns professores apresentaram descrições de um aluno ideal, que eles gostariam de ter nas salas de aula. Segundo os autores, trata-se de um imaginário de "bom" aluno, que já leu sobre o conteúdo da aula, que já fez uma tarefa que supostamente é dele, e que está em sala de aula apenas para tirar as dúvidas que tem sobre o assunto. "Trata-se de um aluno 'idealizado', que todos os professores gostariam de ter em suas aulas, mas que, infelizmente, está distante da realidade na qual convivemos" (QUADROS et al., 2006, p. 8).

Quanto à forma de trabalho do professor, que fez um discurso descritivo daquilo que a ciência considera como uma explicação coerente, Quadros et al. (2006) afirmam que o conhecimento é bastante valorizado, a ponto de, algumas vezes, não se conseguir abrir mão de um determinado conteúdo. Essa dedicação ao conteúdo pode estar fazendo com que o estudante veja, nas atitudes do professor, descaso para com o estudante, que se encontra em formação.

Assim, com o objetivo de entender melhor como as relações de sala de aula do Ensino Superior são consideradas por professores e estudantes deste nível de ensino, desenvolvemos este trabalho.

\section{Organizando o trabalho}

$\mathrm{Na}$ tentativa de buscar indícios que nos permitissem construir respostas às nossas questões-problema, organizamos dois instrumentos de coleta de dados a serem aplicados a uma amostra de professores e de estudantes do Departamento de Química da Universidade Federal de Minas Gerais (UFMG).

Ambos os instrumentos foram construídos para auxiliar na identificação de três pontos básicos: i) características de um professor universitário, segundo os estudantes; ii) características de um estudante universitário, segundo os professores, e iii) características das relações pedagógicas presentes na sala de aula.

Um dos instrumentos de coleta de dados foi entregue a 28 professores do Departamento de Química da UFMG, que lecionam no curso de Licenciatura em Química. Destes, recebemos o retorno de 16. Os professores participantes têm formação em nível de doutorado, em áreas específicas da Química, e desenvolvem atividades no curso há mais de dez anos.

O outro foi entregue a 35 estudantes de graduação em Química da UFMG, a partir do $5^{\mathrm{o}}$ semestre. Consideramos que esses estudantes já tinham maior convivência com os professores e, por isso, poderiam opinar mais criticamente sobre os pontos destacados no questionário. Destes, recebemos 21 questionários preenchidos. Os estudantes participantes pertencem aos cursos de Licenciatura (12) e de Bacharelado (nove) em Química.

Para análise dos dados, lemos conjuntamente em torno de $20 \%$ dos questionários de cada um dos grupos pesquisados e construímos, para cada grupo, um conjunto de categorias. Baseados nestas categorias, cada pesquisador analisou os demais questionários e tabulou os dados de acordo com a categorização feita. 
Quadros, A. L. et al.

\section{Analisando as relações pedagógicas}

A análise dos dois instrumentos de coleta de dados nos deu uma ideia do que dizem os estudantes sobre o trabalho do professor, o que dizem os professores sobre os estudantes que frequentam suas aulas, e como ambos consideram a relação de sala de aula. Para relatarmos o que entendemos, dividimos a nossa análise em três itens, os quais comentamos a seguir:

a) $\mathrm{O}$ que dizem os estudantes?

A tabulação dos dados, referente ao instrumento de coleta de dados dos estudantes, deu origem à Tabela 1, com a qual fazemos a análise.

Tabela 1. Características dos bons professores, segundo os estudantes.

\begin{tabular}{lc}
\hline \multicolumn{1}{c}{ Características dos professores } & Número de citações \\
\hline Boa didática & 18 \\
Domínio de conteúdo & 15 \\
Identificado com a docência & 11 \\
Bom relacionamento interpessoal & 9 \\
Considera/responde aos questionamentos dos alunos & 8 \\
Observador, sensível, perspicaz & 7 \\
É atualizado & 6 \\
Disponível fora da sala de aula & 5 \\
Contextualiza o conteúdo & 5 \\
Exerce autoridade sem ser autoritário & 3 \\
\hline
\end{tabular}

As duas prerrogativas que mais apareceram, relativas a um bom professor, foram o domínio de conteúdo e a boa didática. Como pesquisadores e pela vivência que temos com o ambiente no qual se desenvolveu a pesquisa, já esperávamos esse resultado.

Em relação ao "domínio de conteúdo", podemos partir da premissa de que ninguém ensina aquilo que não sabe. E, por estarmos tratando de professores de Ensino Superior, com formação em pós-graduação, geralmente em nível de doutorado, entendemos que é um ambiente de saberes altamente especializados, dentro da área pela qual cada um deles optou.

No que se refere à "boa didática", não basta saber um determinado conteúdo para ensiná-lo. É preciso considerar, também, como ensinar. Entre os professores de um departamento cuja especialização se deu nas áreas ditas mais "duras" do conhecimento, a discussão sobre como ensinar não se faz tão presente. E isso parece ser sentido pelos estudantes que, no instrumento de coleta de dados, fizeram várias menções ao fato.

Entendemos que o pouco contato com conhecimentos mais ligados ao ensinar e aprender pode ser minimizado quando o professor prepara adequadamente a aula e dedica-se a essa tarefa.

Outro fator que recebeu uma atenção significativa dos estudantes foi o fato de o professor ser "identificado com a docência". Isso decorreu de comentários sobre professores que, aparentemente, não gostam de dar aulas. Os estudantes argumentaram que a identificação com a docência é um fator que exerce influência na qualidade das aulas desses professores. 
Sabe-se que as universidades norteiam seu trabalho por três pilares: ensino, pesquisa e extensão. O professor universitário, na medida do possível, deve envolver-se com estes pilares. Apesar disso, a avaliação dos programas de pós-graduação dessas instituições, feita pelos órgãos que fomentam a pesquisa no país, valoriza a produção científica de cada um dos integrantes do programa, e não o envolvimento com as aulas. Também a aprovação ou não de projetos de pesquisa, feita por esses mesmos órgãos, depende do currículo do solicitante, do qual se espera tenha um bom desempenho na produção científica. Isso leva, como consequência, a uma dedicação maior à pesquisa, o que poderá dinamizar a produção de artigos. $\mathrm{O}$ professor universitário é, então, pressionado a se dedicar mais à pesquisa do que ao ensino, e isso pode dar a impressão de que não se identifica com a docência. Ou, em alguns casos, pode tornar a docência uma carga não desejada no trabalho desse professor, e, assim, objeto ao qual ele não se dedicará com afinco. A atividade docente, para a qual a vaga do professor foi pleiteada pelo departamento e/ou instituto, acaba sendo um entrave à produção científica.

No entanto, são as aulas e as disciplinas que compõem o currículo dos diversos cursos de graduação as responsáveis diretas pela formação dos profissionais. Por isso mesmo, as aulas deveriam receber atenção especial dos professores e da instituição de Ensino Superior.

Em outros comentários de estudantes, percebemos que o bom professor é aquele que "sabe se relacionar" e "considera os questionamentos" a eles feitos, respondendo-os dedicadamente. Ao dirigir uma pergunta ao professor, mesmo que simples ou óbvia, o estudante pode estar apenas demonstrando o seu nível de desenvolvimento real. E, ao responder, o professor estará auxiliando no entendimento. $\mathrm{O}$ fato de alguns professores desconsiderarem determinadas perguntas de estudantes, por envolverem tema já estudado ou por serem questionamento cuja explicação é muito óbvia, considera apenas a lógica de pensar do professor. Ele tem uma formação altamente especializada. Por isso, conhecimentos básicos que, para ele, são extremamente simples, podem ser complexos para os estudantes. Considerar os questionamentos é, portanto, tarefa do professor e sinal de respeito ao saber do estudante.

Outra categoria que apareceu como elogiável no trabalho do professor é o fato de ele "ser observador, sensível e perspicaz". O nosso entendimento desse comentário feito pelos estudantes é de que o professor observador é sensível às necessidades do aluno. Ele é capaz de perceber a alteração no comportamento dentro de sala de aula e a consequente queda do rendimento. Ele se preocupa com o aprendizado ou alguma necessidade especial do estudante. Ele faz esclarecimentos de conteúdo, mesmo que este já tenha sido explicado anteriormente ou não esteja diretamente ligado à disciplina. Além disso, é hábil para gerenciar a aula e notar quando um estudante atrapalha o rendimento dos demais.

Além dessas características, os pesquisados citaram o fato de ser atualizado, estar disponível em horários além dos de sala de aula, contextualizar o conhecimento químico, exercer autoridade sem ser autoritário, ser pontual e organizado.

Porém, para além das características de um bom professor, chamou a nossa atenção o número relativamente alto de argumentos (12) referindo-se a um tratamento inadequado do professor para com os estudantes, na sala de aula. Alguns argumentos usaram palavras que consideramos "pesadas" para descrever um professor específico. Eles se referiam a casos acontecidos em sala de aula nos quais o professor não entendeu as dificuldades que o estudante apresentou e/ou não soube lidar com essas dificuldades.

Acreditamos que uma relação na qual uma das partes espera dedicação e envolvimento e a outra espera apenas um tratamento impessoal e profissional, poderá gerar embates, já 
Quadros, A. L. et al.

que se tratam de duas frações que não se completam numa relação que fundamentalmente precisa estar em sintonia. De um lado, temos o professor - detentor de um conhecimento - e, do outro, o estudante, com objetivos em sua formação que nem sempre são conhecidos pelo professor. O não entendimento dos objetivos de cada uma das partes pode levar a interpretações equivocadas. Tanto o professor pode passar uma sensação de superioridade em sala de aula, como as ações dos estudantes serem consideradas uma afronta ao professor. Observamos comentários de professores sobre alunos que "atrapalham" a aula com perguntas inadequadas ou que tentam chamar a atenção para si ou para outro assunto que não aquele programado para a referida aula. E, em contrapartida, os estudantes pesquisados afirmam que o professor não entende as suas dificuldades e, por isso, não responde a alguns questionamentos e, algumas vezes, trata esse estudante com uma rispidez desnecessária.

\section{b) $\mathbf{O}$ que dizem os professores?}

Grande parte dos professores que participaram desta pesquisa citou, como característica de um bom estudante, o fato de ele ser "participativo, interessado, motivado e dedicado". A Tabela 2 dá uma ideia dos comentários feitos pelos professores.

Tabela 2. Características dos bons estudantes, segundo os professores.

\begin{tabular}{lc}
\hline \multicolumn{1}{c}{ Características dos estudantes } & Número de citações \\
\hline Participativo & 12 \\
Dedicado & 10 \\
Complementa/aprofunda seu estudo & 10 \\
Atento ao professor/conteúdo & 9 \\
Questionador & 6 \\
Raciocínio crítico & 5 \\
Educado & 4 \\
Gosta da disciplina & 4 \\
Tem boas notas & 2 \\
Aceita desafios & 2 \\
Não é imediatista e considera-se em formação & 2 \\
Bem-humorado, assíduo, com base de conhecimentos (cada) & 1 \\
\hline
\end{tabular}

Na maior parte das citações, os professores não demonstraram estar falando de um estudante que, necessariamente, tem as melhores notas. Referiam-se a alguém que participa das aulas, que faz todas as atividades que o professor propõe, que demonstra querer aprender. Parece ser um aluno que não reclama por reclamar, não critica por criticar. Faz ponderações, mesmo que não sejam definitivas, e quando faz um comentário ou explanação, o faz com educação.

Certamente referem-se a um estudante que não quer somente cumprir os créditos, mas que quer participar de um processo de desenvolvimento e amadurecimento que aquele conteúdo/disciplina pode proporcionar.

Por outro lado, apesar de considerarem o aluno participativo como característica elogiável, algumas formas de participação são questionadas. Ao se referirem a estudantes que fazem perguntas, quatro comentários, que não fazem parte da Tabela 2 , mostraram que, além de 
A percepção de professores e estudantes ...

perguntas que se destinam a construção e entendimento de conhecimentos, algumas têm, na visão dos professores, outro caráter que não o de aprendizagem.

Há comentários sobre alunos que perguntam com o intuito de chamar a atenção, provavelmente para construir a imagem de um bom aluno frente à turma, ao professor e até para si próprio. Outros que perguntam para testar o conhecimento do professor. Nesse caso as perguntas são mais abrangentes e extrapolam o conteúdo da aula/disciplina. Também foram citados os estudantes que se dispersam e, ao voltarem a atenção à aula, perguntam sobre um assunto que o professor acabou de explicar, como se não o tivessem escutado. Um último grupo de participantes faz perguntas extremamente óbvias e o professor as percebe como se fossem a ele dirigidas apenas para "irritá-lo".

Para um professor com alto grau de especialização e cuja crença no conhecimento científico seja inquestionável, é muito difícil entender que um determinado conhecimento, que para ele é tão óbvio, não seja entendido pelo estudante.

Outra categoria que percebemos ter aparecido várias vezes nos comentários dos professores refere-se ao estudante "ser atento ao conteúdo e/ou ao professor". Nesse caso, o professor, ao selecionar determinado conteúdo químico, provavelmente tem claro por que o faz e qual a importância daquele conhecimento para o entendimento do todo. Mas é possível que o estudante não tenha essa percepção e, por não entender a necessidade de determinados conhecimentos, não seja capaz de se dedicar inteiramente a ouvir e a aprender.

O papel do professor no "envolvimento" do estudante para com o conteúdo não foi considerado. O professor parece entender que, uma vez ingresso no curso, a função desse estudante é se dedicar aos conhecimentos que nele são ofertados. Pela pouca ou nenhuma participação dos estudantes na seleção dos conteúdos, na maioria das instituições de ensino, essa parece ser uma percepção geral.

Um bom aluno também foi considerado como aquele que "complementa e aprofunda seus estudos" para além da aula. Pareceu-nos claro, em alguns comentários, que o professor espera do estudante mais do que assistir a aula: que este se prepare para ela, que faça leituras extraclasse etc.

Quadros et al. (2006) já haviam identificado que, no imaginário dos professores de Ensino Superior, os alunos já têm autonomia e buscam sempre aprofundar os conhecimentos e fazer leituras que os preparem para assistir e participar das aulas. É possível que, neste caso, o professor esteja considerando que a não participação dos estudantes seja justificada pelo fato de não terem um preparo anterior. Em nenhum momento da fala dos professores houve referência à responsabilidade do professor na seleção e na forma de abordagem do conteúdo.

Foram citadas outras características, em menor número, a saber: gostar da disciplina, aceitar os desafios propostos, não ser imediatista e entender-se como um sujeito em formação, e ter uma base mínima de conhecimentos, para que a disciplina possa ser desenvolvida conforme o planejamento do professor.

\section{c) Como a relação entre professor e estudante é entendida?}

Desde que teorias contemporâneas de ensino e aprendizagem têm considerado a aprendizagem como uma atividade social, mediada pela cultura, a preocupação que se centrava em “o que ensinar" passa a focar, também, o "como ensinar". Esse é um dos focos principais da 
Quadros, A. L. et al.

área de Didática do Ensino e, portanto, da Didática do Ensino de Química. Porém, o que ensinar e como ensinar são permeados por interações entre pessoas e, por isso, recorremos a contribuições de outros campos do saber, tais como: filosofia, sociologia, antropologia e psicologia. No caso da afetividade na relação entre professor e aluno, recorremos à psicologia.

Leite e Tassoni (2002) analisam algumas pesquisas (NEGRO, 2001; SILVA, 2001; TASSONI, 2000) que, usando pressupostos de Vigotski e Wallon, discutem a dimensão afetiva em sala de aula e as influências que essa afetividade poderia ter sobre a aprendizagem. Mesmo considerando a dificuldade metodológica e conceitual em pesquisar a afetividade, os autores argumentam que ela não se restringe apenas a contatos físicos. Segundo eles:

Adequar a tarefa às possibilidades do aluno, fornecer meios para que realize a atividade confiando na sua capacidade, demonstrar atenção às suas dificuldades e problemas, são maneiras bastante refinadas de comunicação afetiva. [...] a afetividade está presente em todos os momentos e etapas do trabalho pedagógico desenvolvido pelo professor, o que extrapola sua relação "tête-à-tête" com o aluno. (LEITE e TASSONI, 2002, p. 125)

Baseados no conceito de afetividade, considerado por Leite e Tassoni (2002), usamos as opções "estritamente profissional" e "profissional e inevitavelmente afetivo" para a relação entre professor e alunos, na sala de aula.

Os resultados encontrados nos dois instrumentos de coleta de dados estão descritos na Tabela 3.

Tabela 3. Entendimento sobre a relação entre professores e estudantes.

\begin{tabular}{lcc}
\hline & Estritamente profissional & Profissional e inevitavelmente afetiva \\
\hline Professores & $06^{*}$ & $11^{*}$ \\
Alunos & 04 & 17 \\
\hline
\end{tabular}

* Um professor assinalou as duas opções.

A análise das justificativas dadas para a escolha entre as duas opções fornecidas nos faz afirmar que a relação afetiva é vista, pela maioria, como vinculada à prática de sala de aula. Mas essa opção foi bem mais significativa entre os estudantes.

Os professores cuja opção incluiu a afetividade mostraram entendê-la como algo inerente à relação humana e que, portanto, está presente em sala de aula. Além disso, esses professores argumentaram que a afetividade aumenta a confiança do aluno no professor, auxiliando a aprendizagem.

Os estudantes entendem a afetividade como necessária, considerando que o conhecimento que está sento trabalhado não é apenas de conteúdo acadêmico, e sim um aprendizado para a vida toda. Como tal, esperam que o professor possa extrapolar o discurso científico sem jamais deixá-lo de lado - e considerar as dificuldades de entendimento do mesmo. Algumas vezes, essas dificuldades se referem a perceber esse conteúdo inserido no mundo. Também esperam um tratamento que inclua aspectos que vão além do conteúdo, tais como: a 
A percepção de professores e estudantes ...

postura, a ética, o respeito, a sensibilidade e outros relativos a necessidades próprias do ser humano.

Mas tanto entre professores quanto estudantes percebemos que, ao optarem pelo "estritamente profissional", estavam preocupados com um tratamento desigual em função de empatia ou afinidades. Nesses casos, a afetividade é vista como uma relação de amizade ou, como citaram Leite e Tassoni (2002), de "tête-à-tête" e que, como tal, comprometeria o lado profissional do ato de ensinar e aprender.

\section{O que aprendemos com as evidências...}

Percebemos claramente que não há um entendimento sobre o que seja afetividade e como ela permeia a sala de aula. Inclusive, pareceu-nos que há um certo "receio" de envolvimento, quando a relação afetiva é vista como uma relação de amizade e de empatia ou afinidade.

A opção "estritamente profissional" referia-se, na maioria das vezes, ao professor que desenvolve o conteúdo e trata a todos igualmente. Mas a sala de aula é um local que reúne os "diferentes". E a ética e o respeito não estariam exatamente em perceber e saber trabalhar com esses diferentes?

Nossa análise dos dados mostrou que o professor espera que os estudantes sejam autônomos em seus estudos e se preparem previamente para as aulas. Não classificam como bom aluno aquele que tira as melhores notas, mas o que se prepara previamente para a aula e busca formação complementar. O professor se sente realizando a sua tarefa - contribuir na formação dos sujeitos - quando percebe o estudante interessado e participativo nas aulas. Apesar disso, a percepção de que algumas formas de participação são criticadas nos faz supor que há requisitos necessários para essa participação.

Já os estudantes, esperam um professor com domínio do conteúdo, boa didática, que seja identificado com a docência, observador, sensível e perspicaz e que considere os questionamentos dos alunos. Eles esperam que o professor entenda os limites e as deficiências de cada um e que tenha sensibilidade para auxiliá-los a se superarem, melhorando, assim, o desempenho. Também pareceram demonstrar que um tratamento igualitário é necessário. Porém, os dados coletados não nos permitem distinguir se esse tratamento igualitário se refere a promover a aprendizagem de todos os sujeitos, considerando as diferenças, explicar o conteúdo desconsiderando a diferença ou, ainda, não dirigir a sua aula a aqueles que têm mais facilidade e condições de participar.

Baseados nas diferentes expectativas percebidas entre estudantes e professores do Ensino Superior, entendemos que não há um "contrato" de trabalho ou uma socialização de agenda preestabelecida na qual conste, além de conteúdo, objetivos e metas, também as expectativas, tanto do professor quanto dos estudantes. Ao que parece, os estudantes não têm claro o que o professor espera deles e o professor também não está sendo capaz de lidar com as expectativas dos estudantes, provavelmente por não as conhecer.

Se considerarmos a natural assimetria, já citada por Brants (2004) e Dias (2007), presente na sala de aula, o não estabelecimento de uma "agenda" ou "contrato" entre as partes apenas continuará criando situações nas quais as expectativas do professor e do estudante são diferentes e divergentes. O professor, cuja posição é privilegiada em relação aos estudantes, deve promover a discussão desta agenda/contrato, de forma a se tornarem mais explícitos os 
Quadros, A. L. et al.

objetivos, as informações a serem compartilhadas, a necessária reflexão sobre estas informações e, enfim, as expectativas de ambas as partes.

Trabalhar nesse universo de "diferentes" certamente é um desafio para os professores, e o gerenciamento da sala de aula é uma tarefa que precisa ser melhor entendida tanto nas instituições de Educação Básica quanto nas de Ensino Superior e, por isso, mais discutida nos cursos de formação de professores.

\section{Referências}

BRANTS, G. W. Estudo da relação poder/submissão em sala de aula a partir da análise da interação conversacional entre professor e alunos. Revista Eletrônica de Divulgação científica em Língua Portuguesa, Linguística e Literatura, v. 1, n. 1, p. 1-10, 2004. Disponível em: < http:/ /www.letramagna.com>. Acesso em: 28 maio 2008.

DIAS, A. P. Conversação e poder: uma estreita relação em sala de aula. In: CONGRESSO DE LEITURA DO BRASIL, 16., 2007, Campinas. Anais...Campinas: Unicamp, 2007. Disponível em: <http://www.alb.com.br/anais16/sem11pdf/sm11ss02_06.pdf>.

Acesso em: 1 abr. 2010.

FREIRE, P. Pedagogia da autonomia. Rio de Janeiro: Paz e Terra, 1996.

LEITE, S. A. S.; TASSONI, E. C. M. A afetividade em sala de aula: as condições de ensino e a mediação do professor. In: AZZI, R.; SADALLA, A. M. (Orgs.). Psicologia e formação docente. São Paulo: Casa do Psicólogo, 2002. p. 113-141.

NEGRO, T. C. Afetividade e leitura: a mediação do professor em sala de aula. 2001. Relatório técnico (Conclusão de bolsa de pesquisa da Faep) - Faculdade de Educação, Universidade Estadual de Campinas, Campinas, 2001.

PANIZZI, C. A. F. L. As relações afetividade-aprendizagem no cotidiano da sala de aula: enfocando situações de conflito. In: ASSOCIAÇÃO NACIONAL DE PÓS-

GRADUAÇÃO EM EDUCAÇÃO, 27., Caxambu. Anais... Caxambu: ANPED, 2004. Disponível em: < http://www.anped.org.br/reunioes/27/gt13/t132.pdf>. Acesso em: 28 maio 2008.

QUADROS, A. L. et al. As aulas dos professores: um olhar para a prática de cada um. Revista Brasileira de Pesquisa e Educação em Ciências, Belo Horizonte, v. 6, n. 1, p. $55-72,2006$.

SILVA, M. L. F. S. Análise das dimensões afetivas nas relações professor-aluno. 2001. Relatório técnico (Conclusão de bolsa de pesquisa da Faep) - Faculdade de Educação, Universidade Estadual de Campinas, Campinas, 2001.

TASSONI, E. C. M. Afetividade e produção escrita: a mediação do professor em sala de aula. 2000. 233f. Dissertação (Mestrado em Educação) - Faculdade de Educação, Universidade Estadual de Campinas, Campinas, 2000.

VALDEZ, D. As relações interpessoais e a teoria da mente no contexto educativo. Pátio Revista Pedagógica, Porto Alegre, v. 23, n. 23, p. 24-26, 2002.

Artigo recebido em setembro de 2009 e aceito em dezembro de 2009. 